\title{
Solar Activity and the Weather
}

\author{
JohN M. WILcoX \\ Stanford University
}

\begin{abstract}
The attempts during the past century to establish a connection between solar activity and the weather are discussed. Some critical remarks about the quality of much of the literature in this field are given. Several recent investigations are summarized. Use of the solar! interplanetary magnetic sector structure in future investigations is suggested to perhaps add an element of cohesiveness and interaction to these investigations.
\end{abstract}

That there is a causal connection between the observed variations in the forces of the Sun, the terrestrial magnetic field, and the meteorological elements has been the conclusion of every research into this subject for the past 50 years. The elucidation of exactly what the connection is and the scientific proof of it is to be classed among the most difficult problems presented in terrestrial physics. The evidence adduced in favor of this conclusion is on the whole of a cumulative kind, since the direct sequence of cause and effect is so far masked in the complex interaction of the many delicate forces in operation as to render its' immediate measurement quite impossible in the present state of science. Before attempting to abstract the results of this research on these points a brief resume of the views held by the leading investigators will be given, especially with the object of presenting the status of the problem to those who are not fully acquainted with this line of scientific literature. The bibliography is large-covers a century-and embraces such names as . . Gauss, Sabine, . . Faraday, Wolf, ... Stewart, Schuster, ... Airy, ... Kelvin, and many others. [Bigelow, 1898]

These words appear to provide a modern and contemporary introduction to an essay on solar activity and the weather, but in fact they were written $75 \mathrm{yr}$ ago. During this interval of $75 \mathrm{yr}$, well over 1000 papers have been published on the subject. It may be fair, then, to ask exactly what has been accomplished.

An appreciable influence of solar activity on the weather is not widely accepted, and is not in everyday use for forecasting purposes. The literature on the subject tends to be contradictory, and the work of the authors tends to be done in isola- tion. It is often very difficult to compare the claims of one author with those of another. Many times an author starts from scratch, rather than building on the work of his predecessors in the classical pattern of science. A widely accepted physical mechanism has not yet emerged.

Nevertheless, there are a few common threads that appear so widely in the otherwise disparate literature as to suggest that they probably have some validity: (1) meteorological responses tend to occur 2 or 3 days after geomagnetic activity; (2) meteorological responses to solar activity tend to be the most pronounced during the winter season; and (3) some meteorological responses over continents tend to be opposite from the responses over oceans.

Many scientists refuse to admit the possibility of an appreciable influence of solar activity on the weather in the absence of an accepted physical mechanism. Such scientists presumably do not use aspirin. This viewpoint is to some extent valid, and we certainly will never rest until we understand the physical mechanisms involved. We may perhaps learn a lesson from history at this point.

In his famous presidential address in 1892 to the Royal Society, Lord Kelvin said a few words regarding terrestrial magnetic storms and the hypothesis that they are due to magnetic waves emanating from the Sun. He considered in particular the magnetic storm of June 25,1885 , and drew the following conclusions (Kelvin, 1892): 
To produce such changes as these by any possible dynamical action within the Sun, or in his atmosphere, the agent. must have 'worked at something like 160 million, 'million, million, million horsepower $\left[12 \times 10^{35}\right.$ regs $\mathrm{s}^{-1}$; which is about 364 times the total horsepower $\left[3.3^{\circ} \times 10^{33}\right.$ ergs $\left.\dot{s}^{-1}\right]$ of the solar radiation. Thus, in this 8 hours of a not very severe magnetic storm, as much work must have been done by the Sun in sending magnetic waves out in all directions through space as he actually. does in 4 months of his regular heat and light. This result, it seems to me, is absolutely con: clusive [emphasis added] against the supposition that ter: restrial magnetic storms are due to magnetic action of the Sun, or to any kind of dynamical action taking place within the Sun, or in connection with hurricanes in his atmosphere, or anywhere near the Sun outside: It seems as if we may also be forced to conclude that the supposed connection, between magnetic storms and sunspots is unreal, and that the seeming agreement between the periods has been a mere coincidence.

These words of an eminent physicist, stated with the absolute assurance that has not completely deserted the profession today, were correct within the frame of reference in which they were uttered. What Lord Kelvin did not know about, and therefore did not take into account in his calculations, was, of course, the solar wind, which extended the Sun's magnetic field lines out past Earth with the field strength decreasing less rapidly than $1 / r^{2}$ rather than as $1 / r^{3}$ as Lord Kelvin had assumed. We may ask today whether there may be an as yet unknown physical process related to solar activity and the weather that is comparable in importance and extent to the solar wind.

A meteorologist's opinion of the subject matter of this symposium is given in the following quotation from Monin (1972):

The greatest attention should be devoted to the question of whether there is a connection between the Earth's weather and the fluctuations in solar activity. The presence of such a connection would be almost a tragedy for meteorology, sinceuit would evidently mean that it would first be necessary to predict the solar activity in order to predict the weather; this would greatly postpone the development of scientific methods of weather prediction. Therefore, arguments concerning the presence of such a connection should be viewed most critically.

\section{INVESTIGATIONS OF THE EFFECT OF SOLAR ACTIVITY ON THE WEATHER}

Having been unable to find in the voluminous literature a single coherent structure to describe and discuss in this paper, I shall proceed by citing a few recent reviews as sources for a bibliography, and then discuss a few recent representative investigations. Some recent reviews and discussions include Rubashev (1964), Schuurmans (1969), Markson (1971), Roberts and Olson (1973b), and Svalgaard (1973). A good cross-section of current activity in the field was given by the papers at the International Union of Geodesy and Geophysics symposium entitled "Solar Corpuscular Effects on the Stratosphere and Troposphere" held in Moscow, August 1971. The symposium papers are in press. Fifty reports and communications were presented at the first All-Union conference entitled "Solar-Atmospheric Relationships in the Theory of Climate and Weather Forecasting" held in Moscow in 1972. A short description of this conference is included as appendix A.

A prominent line of investigation during the past decade or longer has been led by $W$. $O$. Roberts with the participation of $\mathrm{R}$. H. Olson, N. J. Macdonald, D. D. Woodbridge, and T. W. Pohrte. I shall describe only the récent work of Roberts and Ólson, but this, of course, has benefited from the earlier contributions. Roberts and Olson (1973a) have studied the development of 300-mb low-pressure trough systems in the North Pacific and North America region. They find that troughs that"enter- (or are formed in) the Gulf of Alaska 2 to 4 days after a sharp rise of geomagnetic activity tend ${ }^{\prime}$ to be of larger than average size. In this investigation, each trough is characterized by an objectively derived vorticity area index, which is defined as the area of the trough for which the absolute vorticity is greater than or equal to $20 \times 10^{-5} \mathrm{~s}^{-1}$ plus the area greater than or equal to $24 \times 10^{-5} \mathrm{~s}^{-1}$. The study included the winter half years $1964^{\circ}$ to 1971 . Some results of this investigation are shown in figure 1. During 3 to 5 days after the geomagnetic key day, the troughs preceded by a sharp rise in geomagnetic activity have on the average about 40 percent larger vorticity area index than the troughs preceded by a geomagnetically quiet 10 -day period. The statistical analysis given by these investigators appears to be compelling and to eliminate any probability of the results being associated with a statistical fluctuation.

The investigations of Roberts and Olson 


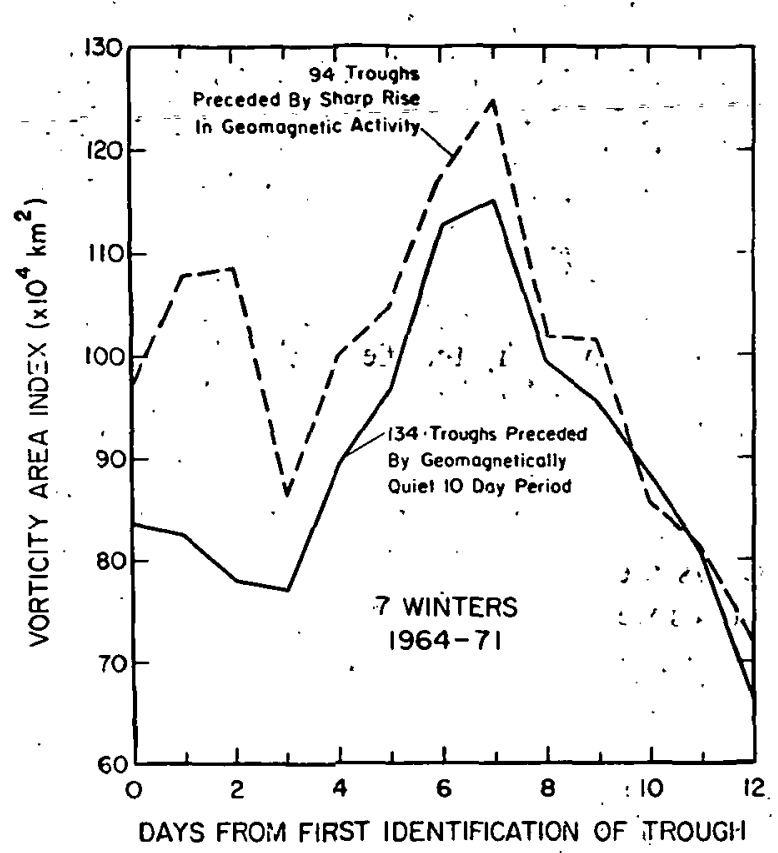

FIGURE 1.-Mean vorticity area index for troughs preceded by sharp geomagnetic activity increases and for troughs preceded by $a^{\prime}$ 10-day geomagnetically quiet period. (For the key troughs add 3 days, on the average, to the lags shown, to ascertain the number of days since the geomagnetic rise that led to the designation as a key trough.) (Roberts and Olson, 1973a.)'

(1973a) were extended by Wilcox et al. (1973a): The vorticity area index was. summed over the portion of the northern hemisphere north of $20^{\circ} \mathrm{N}$, and the time at which an interplanetary magnetic sector boundary was carried past Earth by the solar wind was used as the zero time in a superposed epoch analysis. We emphasize again that the sector boundary provides a ,well-defined time but that the meteorological response is associated with the làrge-scale sector structure during the interval of several days before and after the passing of the boundary, as will be discussed in more detail. The results of the investigation shown in figure $\dot{2}$ indicate that the vorticity, area index reaches a minimum about 1 day after the passing of the sector boundary, followed by. an increase in magnitude of approximately 10 percent during the next 2 or 3 days. The result persists essentially unchanged as the list of sector boundary times is divided in two in three different ways. In a continuation of this investigation, Wilcox et al. $(1973 b)$ found that the effect is present at all

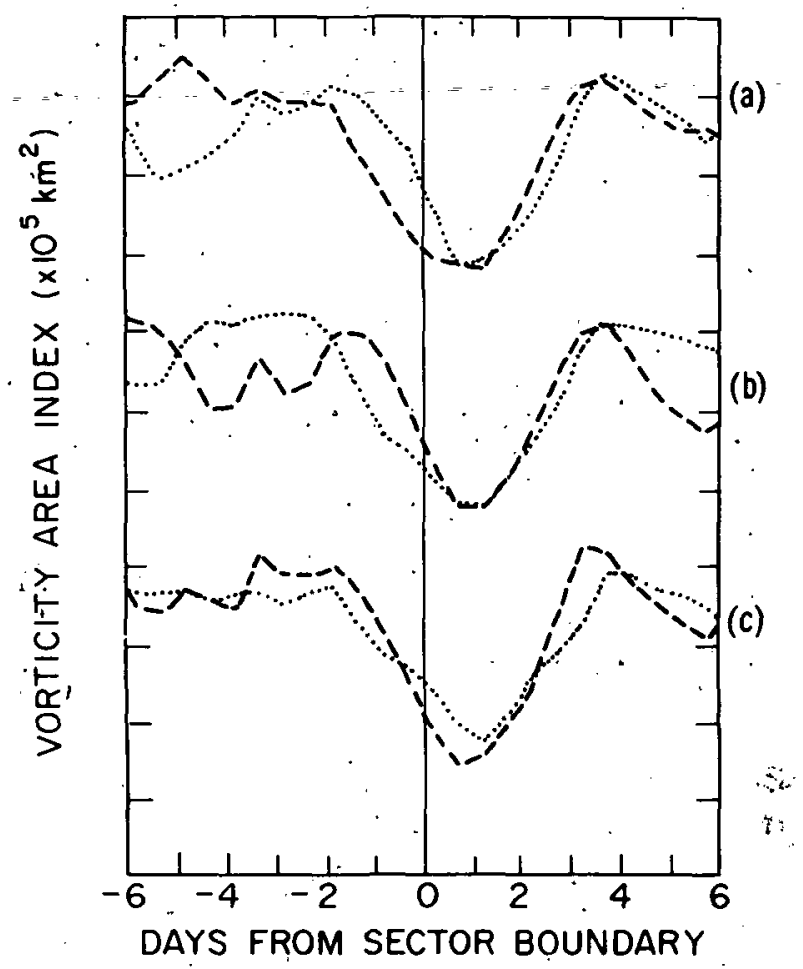

FIGURE 2.-Average response of the vorticity area index to the solar magnetic sector structure. Sestor boundaries were carried past Earth by the solar .wind on day 0 . The analysis includes 54 boundaries during the winter months of November to March in the years 1964 to 1970. The boundáries were divided into two parts according to the magnetic polarity change at the boundary, the first or last half of winter, and the yearly intervals 1964 to 1966 and 1967 to 1970 . (a) The dotted curve represents 24 boundaries in which the interplanetary magnetic field polarity changed in direction from toward the Sun to away from the Sun, and the dashed curve represents 30 boundaries in which the polarity changed from away to toward. (b) The dotted curve represents 32 boundaries in the interval November 1 to. January 15 and the dashed curve represents 22 boundaries in the interval January $16^{\text {to }}$ March 31. (c) The dotted curve represents 26 boundaries in the interval 1964 to 1966 and the dashed curve represents 28 . boundaries in the interval 1967 to 1970 . The curves have been arbitrarily displayed in the vertical direction, each interval on the ordinate axis being $5 \times 10^{5} \mathrm{~km}^{2}$ (Wilcox et al., $1973 a, b)$.

levels in the troposphere but only in the lowest portion of the stratosphere. The effect is not confined to a single interval of longitude or of latitude. Because this meteorological response is related to a well-defined solar structure, it is not subject to the criticism of Hines (1973). 
Another prominent investigation during the past decade or longer is the work of E. R. Mustel (1972). Mustel has investigated the response of the ground level atmospheric pressure to geomagnetic moments based on the first day when an isolated geomagnetic storm becomes sufficiently strong. Mustel finds that in some regions of the globe the atmospheric pressure increases after the geomagnetic moment, whereas in other places the pressure decreases. The reaction time is about 3 . days and tends to increase with decreasing latitude. Figure 3 shows a representative result obtained by Mustel (1972) for the months December, January, and February of the years 1890 to 1967. Large contiguous areas represented by the black circles have an increase in atmospheric pressure after geomagnetic disturbance, while other large areas represented by the open circles have a decrease. The mean -statistical curves for the corresponding regions $\mathrm{I}$ to $\mathrm{VI}$ are shown at the bottom of figure 3 .

Interplanetary magnetic field lines directed away from the Sun can connect most readily with geomagnetic field lines directed into the northern polar cap, and interplanetary magnetic field lines directed toward the Sun can connect most readily with geomagnetic field lines directed out of the southern polar cap. Thus in a given polar cap one might perhaps find changes in meteorological phenomena depending on the polarity of the interplanetary magnetic field. Mansurov et al. (1972) have found such an effect in the atmospheric pressure, using observations obtained during 1964. At a northern polar cap station (Mould Bay, near

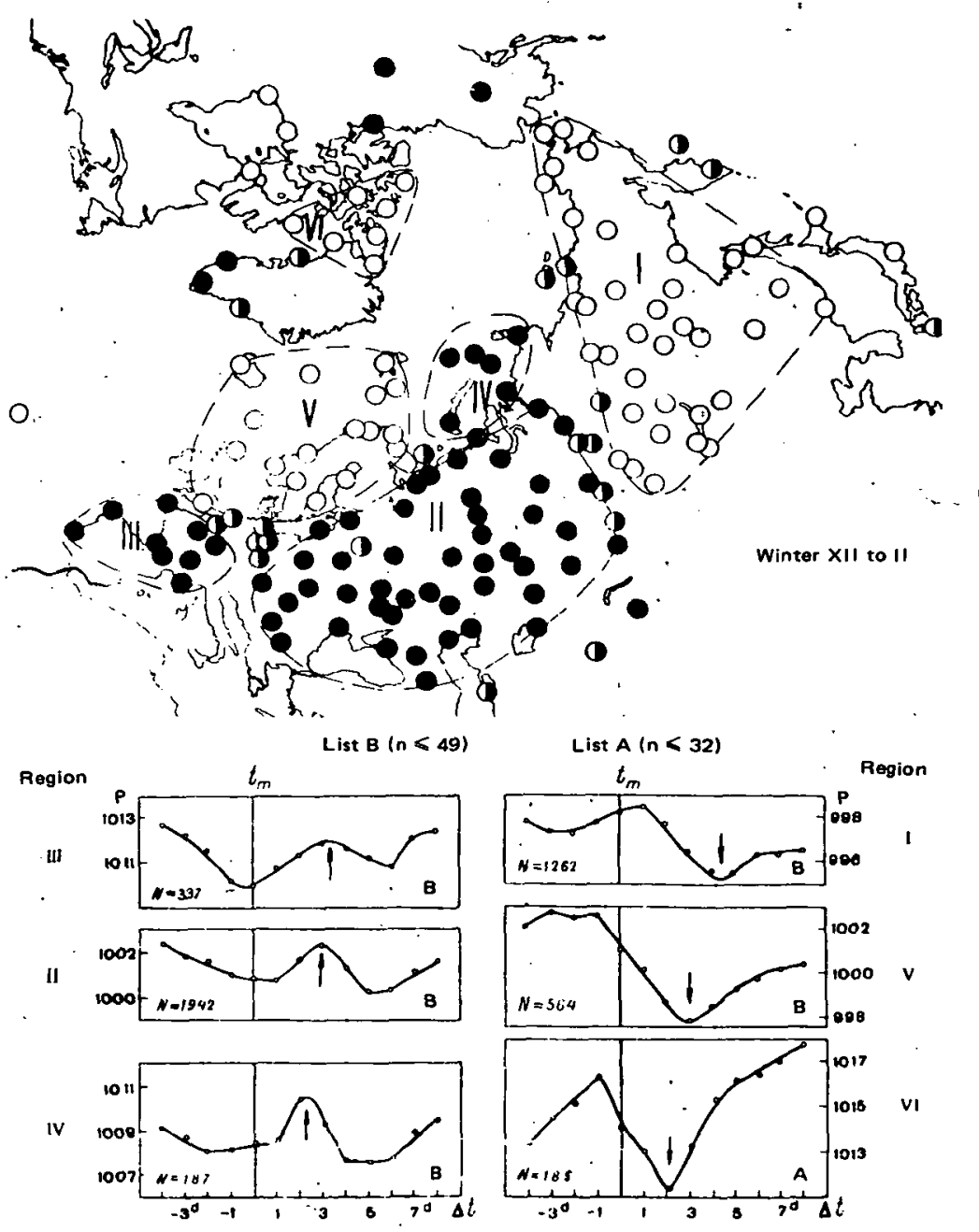

Figure 3.-Hemispheric distribution of the change of atmospheric pressure after a geomagnetic storm for the months of December through February and the years 1890 to 1967 . The black circles correspond to an increase in pressure and the open circles correspond to a decrease in pressure. At the bottom of the figure the mean statistical curves for the regions I to VI are given (Mustel, 1972). ( $n=$ number of stations reporting; $t=$ time in days from 3 days before $t_{\mathrm{m}}$ to 7 days after $t_{\mathrm{m}}$, $t_{m}=$ first day when an isolated geomagnetic storm becomes sufficiently strong to be recorded; $\boldsymbol{P}=$ atmospheric pressure in millibars; and $N=$ number of cases in the analysis of data from a particular region.) 
$80^{\circ} \mathrm{N}$ ) they found that the average pressure was higher when the interplanetary magnetic field was directed toward the Sun, and at a conjugate southern polar cap station .(Dumond d'Urville, near $80^{\circ} \mathrm{S}$ ) the average pressure was higher when the interplanetary magnetic field was directed away from the Sun. Using only days in the first half of each interplanetary 'sector, they obtained the results shown in table 1 .

TABle 1.-Average Atmospheric Pressures

Resulting From Variations in Interplanetary Magnetic Field Direction

\begin{tabular}{ccc}
\hline Location & $\begin{array}{c}\text { Interplanetary } \\
\text { field }\end{array}$ & $\begin{array}{c}\text { Pressures, } \\
\text { millibars }\end{array}$ \\
\hline \multirow{2}{*}{ Northern polar station } & Away & 1011.1 \\
& Toward & 1016.3 \\
Southern polar station & Away & 986.2 \\
& Toward & 982.7 \\
\hline
\end{tabular}

When the entire interplanetary sectors were used (not just the first half of each), the same results were found, but the magnitude of the differences decreased. This is consistent with the observed properties of the interplanetary sector structure, because the average solar wind velocity and interplanetary field magnitude are larger in the first half of the sectors. The authors state that the results are valid with a statistical probability in excess of 99.5 percent.

Schuurmans (1969) has studied the influence of solar flares on the tropospheric circulation. The mean change in height of atmospheric constant pressure levels during the first $24 \mathrm{hr}$ after a flare is greater than may be expected from mere random fluctuations in height. Average positive height changes are found to occur in the midlatitude belts of $45^{\circ}$ to $65^{\circ}$, while average negative height changes prevail poleward of $70^{\circ}$ latitude. The maximum effect is found at approximately the $300-\mathrm{mb}$ level, and the effect appears to be stronger in winter than in the other seasons of the year. Significant mean height. changes are found to occur only during the first $24 \mathrm{hr}$ after a flare except at the ground level where significant changes do not appear until the third day after a flare. Schuurmans ascribes the causal agent to the corpuscular radiation of the flare rather than to
UV radiation. A representative rèsult is given in figure 4 showing that zonal averages of the pattern of $500-\mathrm{mb}$ height changes as a function of latitude are approximately the same in the northern and the southern hemispheres.

Shapiro and Stolov (1972) have found significant increases in westerly winds at the $700-\mathrm{mb}$ level in the longitude belt from $90^{\circ}$ to $180^{\circ} \mathrm{W}$ approximately 3 or 4 days after magnetic storms. The effect results mainly from pressure falls in higher latitude $\left(70^{\circ} \mathrm{N}\right)$ but also résults partly from pressure rises at lower latitudes $\left(20^{\circ} \mathrm{N}\right)$ and as usual is strongest in winter. Shapiro (1972) has also found a heightened persistence of sea level barometric pressure over North America and Europe in the first week after a geomagnetic storm, followed by decreased persistence in the second week.

Markson (1971) has studied thunderstorm activity as a function of Earth's position in a solar magnetic sector during 15 solar rotations in 1963 and 1964. The results shown in figure 5 suggest a maximum in thunderstorm activity when Earth was at the leading edge of a sector with magnetic field directed toward the Sun and at the trailing edge of a sector with magnetic field directed away from the Sun; that is, that thunderstorms maximized when Earth was crossing from an away sector into a toward sector. Bossolasco et al. (1972) have found that in the third and especially in the fourth day after the occurrence of an $\mathrm{H}_{a}$ flare, the global thunderstorm activity becomes higher than normal, increasing, on the average, up to 50 to 70 percent, as shown in figure 6 . Reiter (1973) has found an increase in the frequency of influxes of stratospheric air masses down to $3 \mathrm{~km}$ after the occurrence of $\mathrm{H}_{a}$ flares. This is detected through an increased concentration of the radionuclides $\mathrm{Be}-7$ and $\mathrm{P}-32$ at the measuring station at Zugspitze Peak in the Bavarian Alps. These radionuclides are preponderantly generated in the lower stratosphere. Some results are shown in figure 7 .

The largest meteorological response to solar activity occurs during winter. This is such a prominent and persistent feature in the literature that any magnetospheric or geomagnetic effects that show a large variation between winter and summer should be carefully considered in the search 


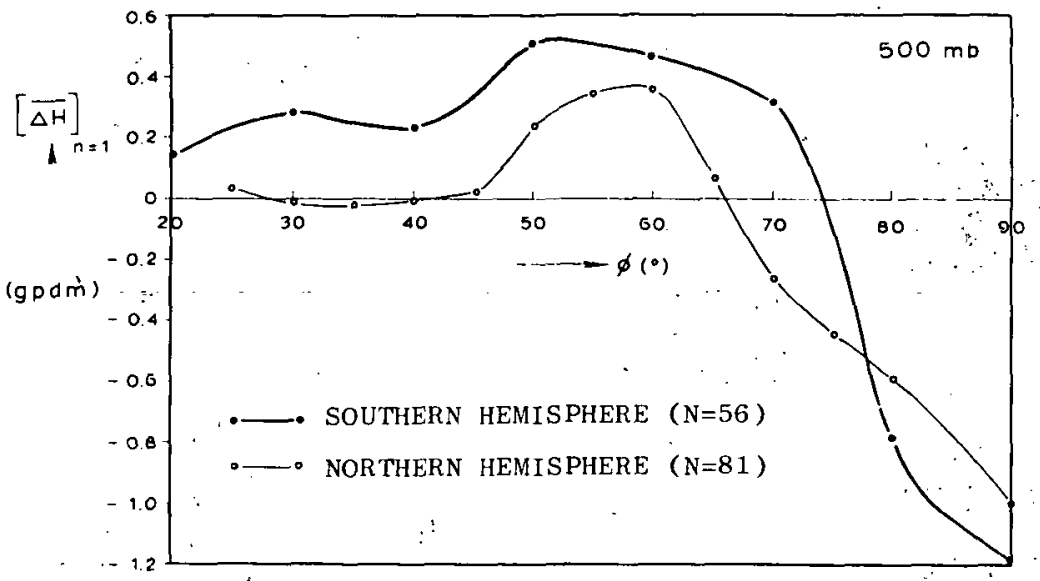

FIGURE 4.-Zonal averages of the difference in height of the 500 mb level between the first aerological observation after a fiare and the observation $24 \mathrm{hr}$ ear: lier as a function of latitude for both hemispheres (Schuurmans, 1969). (gpdm=geopotential dynamic meters; $N=$ number of cases in sample.)

Figure 5.-Thunderstorms as a function of Earth's position in a solar sector: negative sectors (top curve); positive sectors (bottom curve); transitions to adjacent sectors of opposite sign seen at days 0 and 8; all points shown to indicate variance in data; curves drawn through locus of points closest to each daily increment of time; numbers in points give days in sector being normalized, that is, each point is average for all sectors of that length at that increment of the sector's length (Markson, 1971).

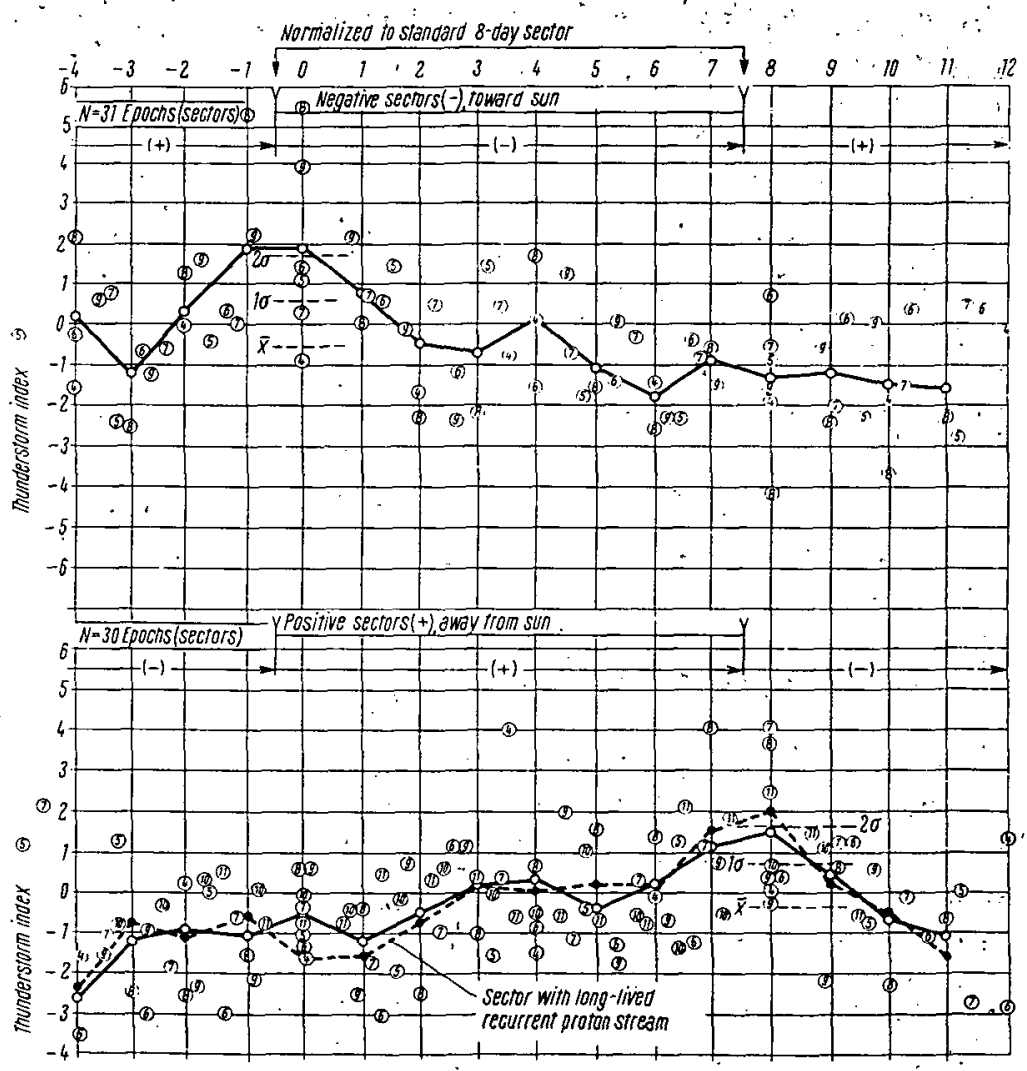

for physical mechanisms. For example, Berko and Hoffman (1974) have studied high-latitude fieldalined $2.3-\mathrm{keV}$ electron precipitation data from OGO 4 at heights of approximately $800 \mathrm{~km}$ during the interval July 1967 through December 1968. This precipitation was found to occur primarily in a roughly oval-shaped region, with the greatest number of field-alined events observed in the magnetic latitudes from $67.5^{\circ}$ to $72.5^{\circ}$ and from 1 to 22 hr. Figure 8 shows the probability of this $2.3-\mathrm{keV}$ electron precipitation being fieldalined for the four seasons as a function of altitude, with the largest probability at high latitudes observed during winter. This result is interpreted by the authors in terms of a possible seasonal dependence in the altitude of double charge layers that may accelerate the electrons.

If other spacecraft experimenters could 'be 

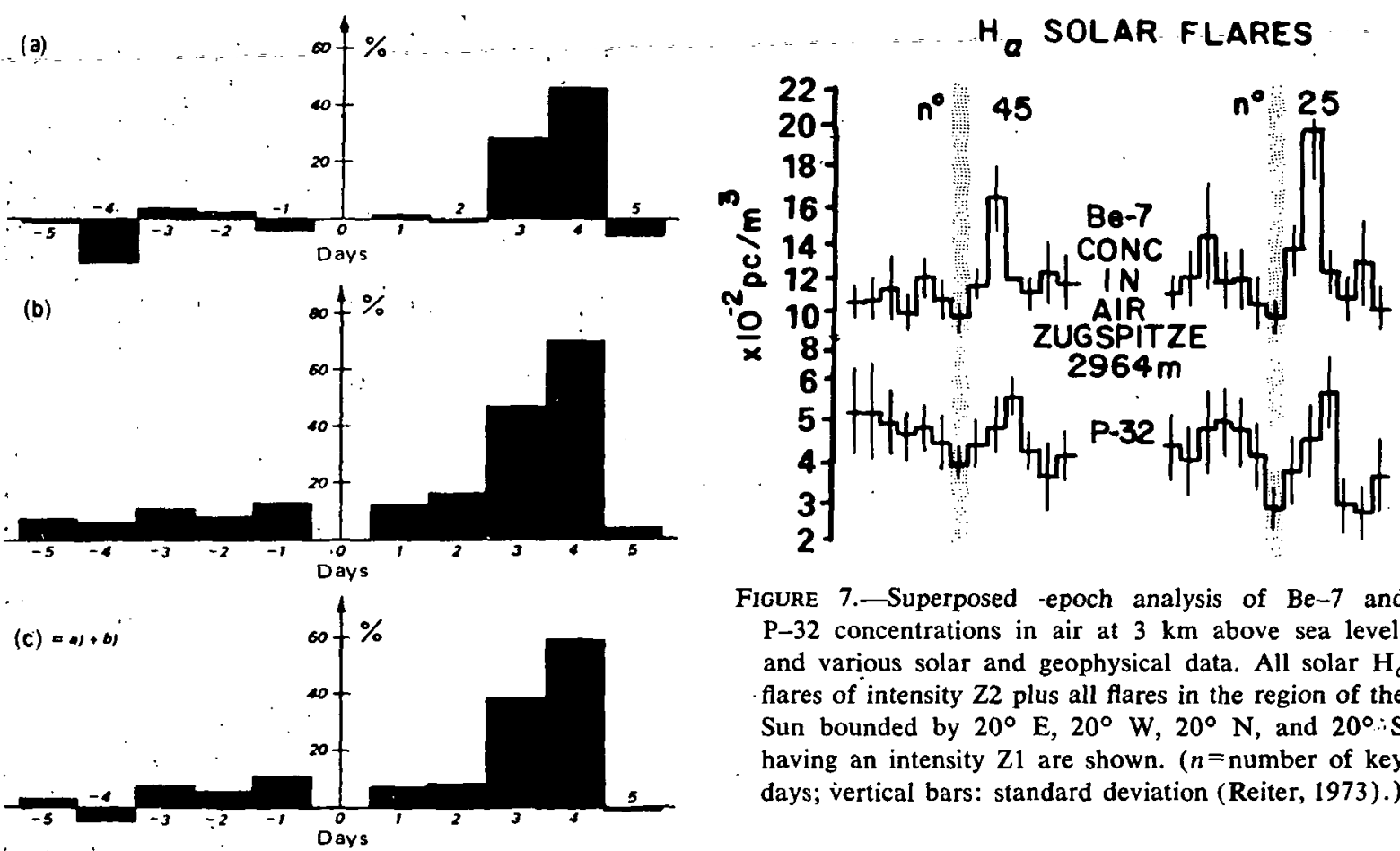

FIGURE 6.-Superposed-epoch analysis of the thunderstorm activity before and after $\mathrm{H}_{a}$ flare day (with $\mathbf{H}_{\alpha}$ flare day as a key day). Data are expressed in terms of percent differences from the value corresponding to the key day (Bossolasco et al., 1972). (a) 1961 to 1965. (b) 1966 to 1970 . (c) 1961 to 1970.

encouraged to analyze their data in terms of the four seasons, it seems possible that valuable clues to the physical mechanisms involved in the effects of solar activity on the weather might result.

The investigations described represent a tiny fraction of the voluminous literature. I do not claim that they are necessarily the most significant. Indeed, it is quite clear that the most important papers on the subject of solar activity and the weather remain to be written. It appears reasonable to expect that the next few years may see more solid progress than has occurred in the previous 75-yr interval.

\section{THE SOLAR/INTERPLANETARY MAGNETIC SECTOR STRUCTURE}

Having criticized the existing literature as being fragmented, disconnected, and unrelated, I would like to suggest a possible remedy. We should utilize the large advances in solar/terrestrial

FIGURE 7.-Superposed -epoch analysis of $\mathrm{Be}-7$ and $\mathrm{P}-32$ concentrations in air at $3 \mathrm{~km}$ above sea level, and various solar and geophysical data. All solar $\mathbf{H}_{a}$ flares of intensity $\mathrm{Z2}$ plus all flares in the region of the Sun bounded by $20^{\circ} \mathrm{E}, 20^{\circ} \mathrm{W}, 20^{\circ} \mathrm{N}$, and $20^{\circ}: \mathrm{S}$ having an intensity $\mathrm{Z} 1$ are shown. ( $n=$ number of key days; vertical bars: standard deviation (Reiter, 1973).)

physics that have occurred during the past decade through the advent of spacecraft, much improved ground-based observations, and the availability of large computers. A common organizing influence to which many of the existing investigations could be related is the solar and interplanetary magnetic sector structure. I will give a brief description of this structure, and then comment on its possible advantages for investigations of solar activity and the weather. The following discussion is taken from Wilcox et al. (1973b).

Figure 9 shows spacecraft observations of the polarity (away from or toward the Sun) of the interplanetary magnetic field observed near Earth during $21 / 2$ solar rotations. The plus and minus signs at the periphery of the figure represent the field polarity during 3-hour intervals (plus indicates away from the Sun and minus indicates toward the Sun). The four Archimedes spiral lines coming from the Sun represent sector boundaries inferred from the spacecraft observations. Within each sector the polarity of the interplanetary field is predominantly in one direction. The interplanetary field lines are rooted in the Sun, and so the entire field pattern rotates with the Sun with an approximately 27 -day period. The solar magnetic sector structure is extended outward from 


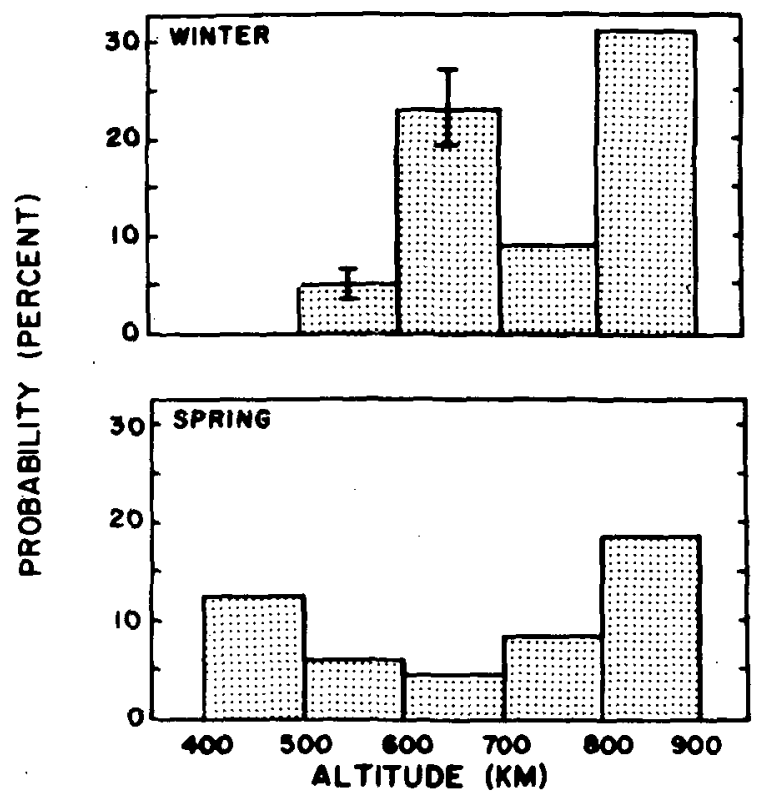

FIGURE 8.-Probability of $2.3-\mathrm{keV}$ electron precipitation being field alined for the four seasons as a function of altitude in the mean local time interval of $22 \mathrm{hr}$ to $1 \mathrm{hr}$. The seasons are defined as equal time intervals around the equinoxes and the solstices. During winter at high altitudes the probability is much larger than during the other seasons (Berko and Hoffman, 1974).

the Sun by the radially flowing solar wind. The sector boundaries are often very thin, sometimes approaching a proton gyroradius in thickness. The. time at which such boundaries are swept past Earth by the solar wind can therefore often be defined to within a fraction of an hour.

What would a sector boundary shown in figure 9 look like on the visible solar disk? Wilcox and Howard (1968) have compared the interplanetary field observed by spacecraft near Earth with the solar photospheric magnetic field deduced from the longitudinal Zeeman effect measured at the 150-ft solar tower telescope at Mount Wilson Observatory. This analysis suggested that an average solar sector boundary is similar to the schematic shown in figure 10 . The boundary is approximately in the north-south direction over a wide range of latitudes on both sides of the Equator. A large area to the west of the boundary has a large-scale field of one polarity and a large-

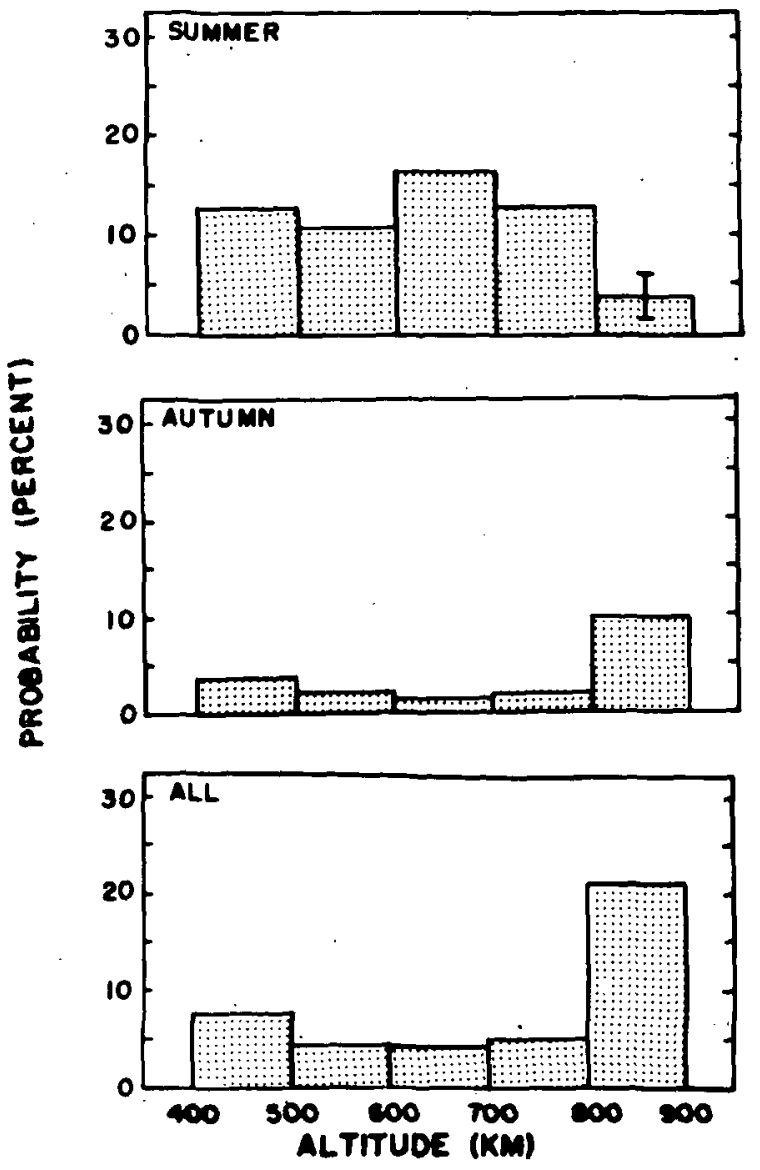

scale region to the east of the boundary has a field of the opposite polarity.

Suppose we observe the mean solar magnetic field when the configuration is as shown in figure 10. The mean solar magnetic field is defined as the average field of the entire visible solar disk; that is, the field. of the Sun observed as though it were a star: In the circumstances shown in figure 10 , such an observation would yield a field close to zero, because there would tend to be equal and opposite contributions from the left and right sides of the figure. One day later the boundary will have rotated with the Sun $13^{\circ}$ westward, and the visible disk will be dominated by the sector at the left in figure 10. A mean field observation will now yield a field having the polarity appropriate to the dominant sector. This same polarity will be observed during several subsequent days, until the next sector boundary passes 


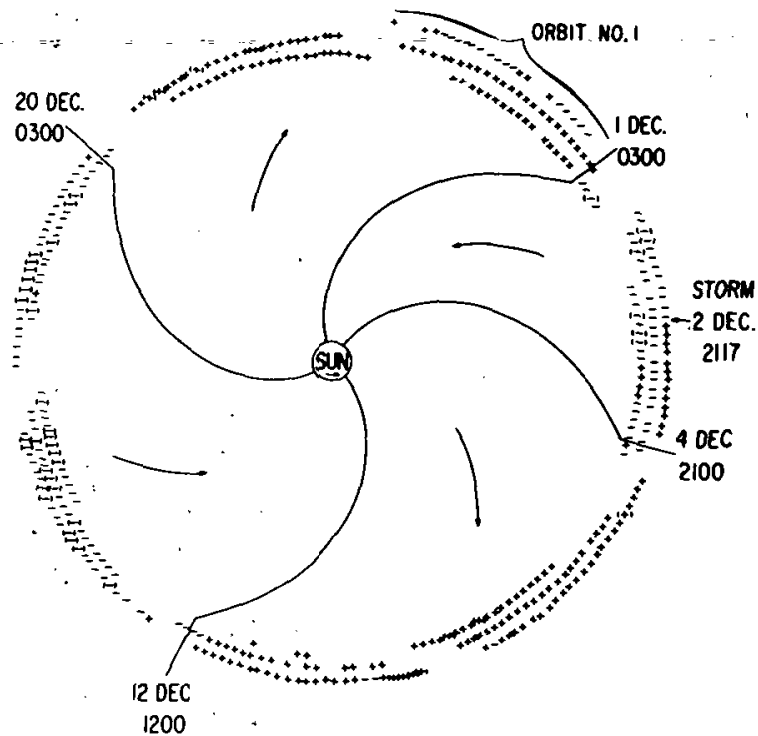

Figure 9,-The inner portion of the figure is a schematic representation of a sector structure of the interplanetary magnetic field that is suggested by observations obtained with the IMP 1 spacecraft flight in 1963. The signs at the circumference of the figure indicate the direction of the measured interplanetary magnetic field during successive 3-hr intervals (plus indicates away from the Sun and minus indicates toward the Sun). The deviations about the average streaming angle that are actually present are not shown (Wilcox and Ness, 1965).

central meridian and reverses the polarity of the observed mean solar field.

Figure 11 shows a comparison of the mean solar field observed at the Crimean Astrophysical Observatory with the interplanetary magnetic field observed with spacecraft near Earth (Severny et al., 19.70). In this comparison, the mean solar field has been displaced by $4 \frac{1}{2}$ days to allow for the average transit time from near the Sun to Earth of the solar wind plasma that is transporting the solar field lines, past Earth. We see in figure 11 that in polarity and also to a considerable extent in magnitude the interplanetary field carried past Earth is very similar to the mean solar magnetic field. If we use the observed interplanetary field to investigate effects on Earth's weather, we are using a structure that is clearly of solar origin but is observed at precise times near Earth.

In addition to the sharp, well-defined change of polarity at the boundary, the sector structure

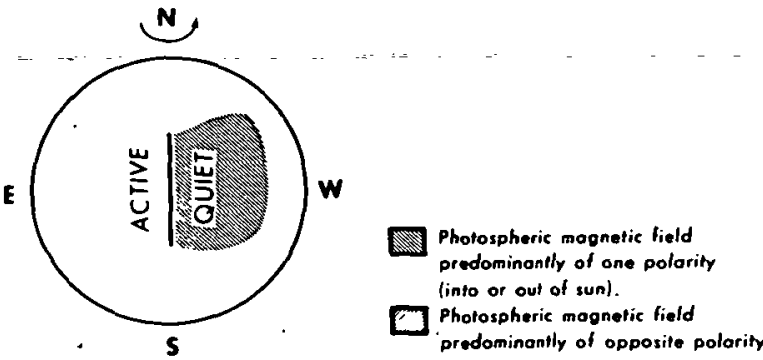

FigURE 10.-Schematic of an average solar sector boundary. The boundary is approximately in the northsouth direction over a wide range of latitudes. The solar region to the west of the boundary is unusually quiet, and the region to the east of the boundary is unusually active (Wilcox, 1971).

has a large-scale pattern. During the several days before a boundary is observed to sweep past Earth (or equivalently we may say during several tens of degrees of heliographic longitude westward of a boundary), conditions on the Sun, in interplanetary space, and in the terrestrial environment tend to be quieter than average. Similarly, after the boundary these conditions tend to be more active than average. A specific example of this is shown in figure 12, which shows a superposed epoch analysis of the average effect on the geomagnetic activity index $K_{p}$ as sector boundaries sweep past Earth. In the days before a boundary, the average geomagnetic activity has a monotonic decline to a minimum about 1 day before the boundary. Activity then rises to a peak 1 or 2 days after the boundary, and then resumes its decline (Wilcox and Colburn, 1972). The Van Allen radiation belts "breathe" inward and outward as the sector structure sweeps past Earth (Rothwell and Greene, 1966). Several other examples of the large-scale geomagnetic response to the sector structure have been given by Wilcox (1968). We emphasize that although the moment at which a sector boundary is carried past Earth provides a well-defined timing signal, the terrestrial effects are related for the most part to the large-scale structure existing for several days on each side of the boundary.

From this discussion it appears reasonable to use the solar magnetic sector structure in an investigation of possible effects on Earth's weather. The use of the sector structure for this purpose has several advantages. We are using a funda- 

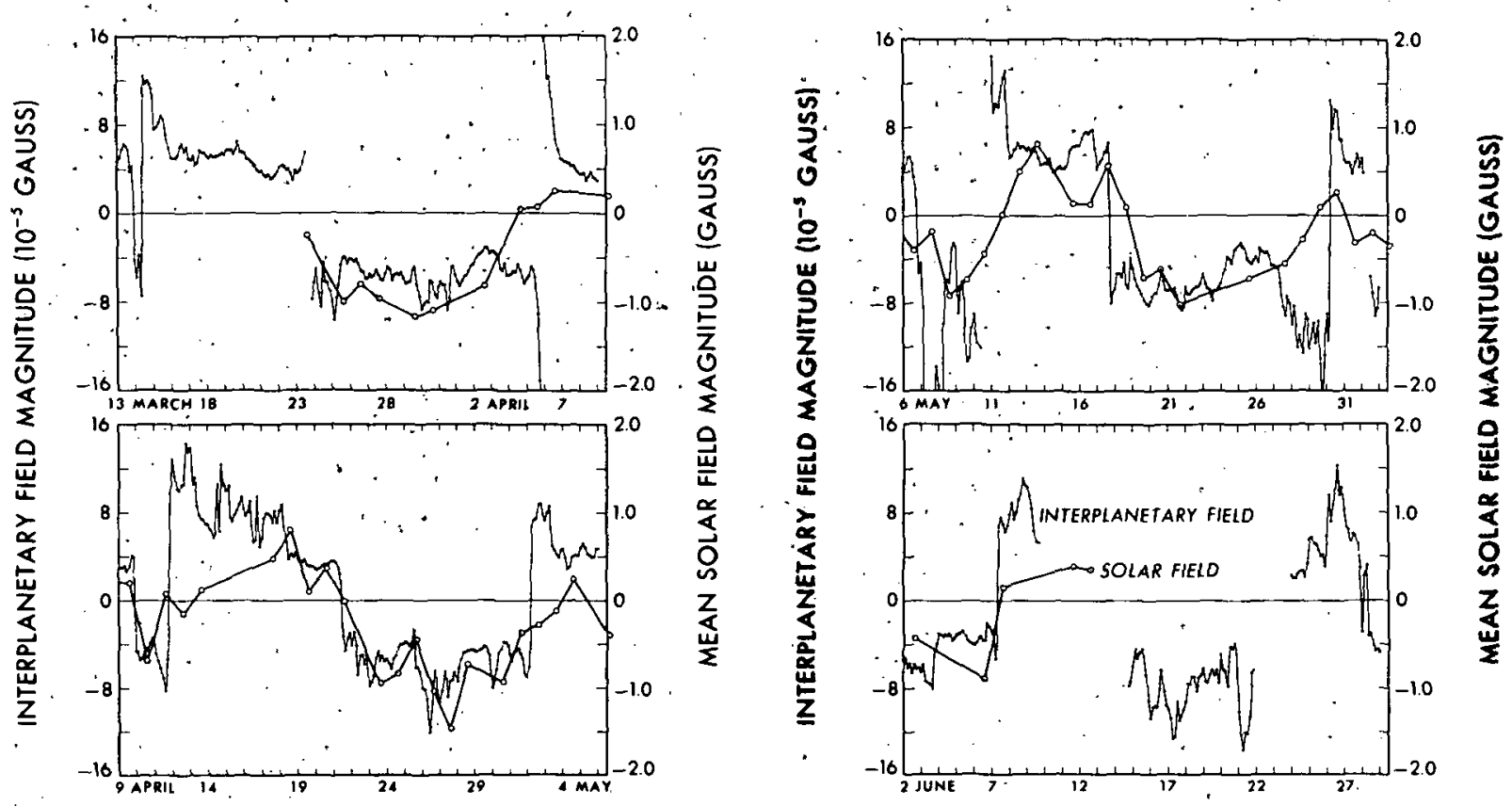

FIGURE 11.-Comparison of the magnitude of the mean solar field and of the interplanetary field. The open circles are the daily observations of the mean solar field, and the dots are 3-hr average values of the interplanetary field magnitude observed near Earth. The solar observations are displaced by $4 \frac{1}{2}$ days to allow for the average Sun-Earth transit time. The abscissa is the time of the interplanetary observations (Severny et al., 1970).

mental large-scale property of the Sun. There can then be no doubt that any observed atmospheric response to the passing of a sector boundary is ultimately caused by the solar magnetic sector structure. We emphasize that "solar magnetic sector structure" is a name for the entire structure discussed. When we say that an atmospheric response is caused by the solar magnetic sector structure, we include possibilities that the effect has been transmitted through interplanetary space in the form of magnetic fields, solar wind plasma, energetic particles, or radiation. Similarly, an atmospheric effect observed in the troposphere may flow through the higher atmospheric layers in an exceedingly complex manner.

We discuss some further advantages of the sector structure for such investigations. In the sense just discussed, a tropospheric response does not have its ultimate cause in other atmospheric processes. Some earlier investigations of solar activity and the weather have been criticized in this respect by Hines (1973). Because of the 4- or 5-day transit time of the solar wind plasma from the Sun to Earth, we can have, by observing the mean solar magnetic field, a 4- or 5-day forecast of that time at which a sector boundary will sweep past Earth. By improving the solar observation procedure, we may be able to detect a sector boundary 2 or 3 days after it has rotated past the eastern limb of the Sun.' This would add an additional 4 or 5 days to the forecast interval.

From one solar rotation to the next, the sector structure usually does not change very -much. In the course of a year there are often significant changes in the sector structure, which appears to have significant variations through the 11 -yr sunspot cycle '(Svalgaard; 1972). All of these regularities and recurrence properties may be of significant assistance in forecasting. As the solar magnetic sector structure and its interplanetary and terrestrial consequences become better underștood in the coming years, the possibilities of using solar data in weather forecasting should also improve.

A list of observed and well-defined sector boundaries is given in appendix B. If it were 


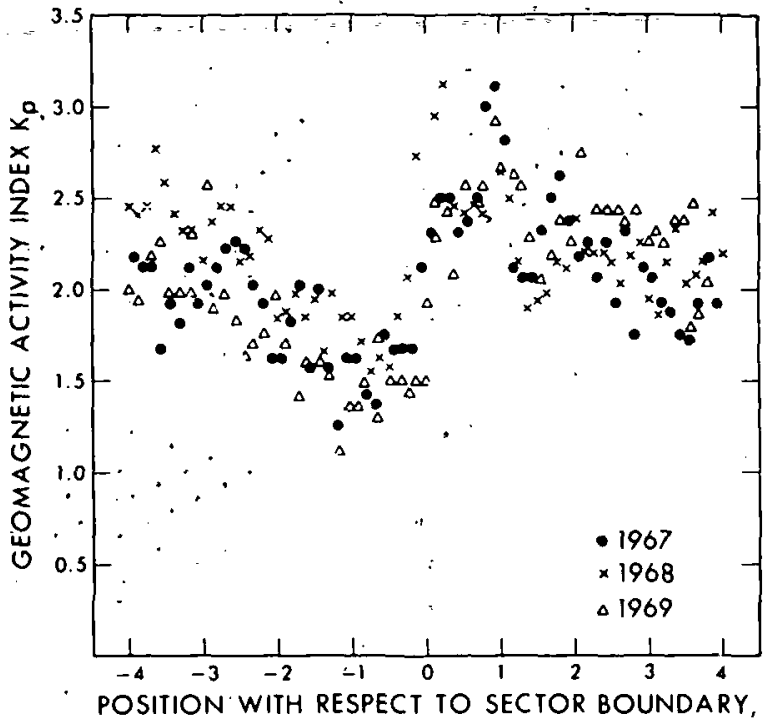

DAYS

FIGURE 12.-Superposed-epoch analysis of the magnitude of the planetary magnetic $3-\mathrm{hr}$ range indices $K_{p}$ as a function of position with respect to a sector boundary. The abscissa represents position with respect to a sector boundary, measured in days, as the sector pattern sweeps past Earth (Wilcox and Colburn, 1972).

possible for investigators in this field to agree on the use of this list for at least one small part of their investigations, an important element of cohesiveness and interaction might be added to the literature.

Having started with a quotation from Bigelow written in 1898, I would like to end with a quotation from E. N: Parker from the Calgary conference on "Solar Terrestrial Relations"' in 1972:

The information on hand indicates a strong and important connection between geomagnetic activity and weather. So if the statistics need improving, let us improve them through further studies. If a physical connection is missing, then we have before us the fascinating task of discovering it. Then perhaps in a few years we can bring a significant improvement to the forecasting of weather in the populated areas of Canada and the United States. We may suppose that a similar connection between geomagnetic activity and the formation of storms exists in other parts of the world too, and can be discovered if sought after.

\section{ACKNOWLEDGMENTS}

I thank Leif. Svalgaard for helpful discussions during the preparation of this paper. This work was supported in part by the Office of Naval Research under Contract N00014-67-A-0112-0068, by the National Aeronautics and Space Administration under Grant NGR 05-020-559, and by the Atmospheric Section of the National Science Foundation under Grant GA-31138.

\section{APPENDIX A-CONFERENCE ON SOLAR- ATMOSPHERIC RELATIONSHIPS - IN THE THEORY OF CLIMATE AND WEATHER FORECASTING}

The first All-Union conference on the problem "Solar-Atmospheric Relationships in the Theory of Climate and Weather Forecasting" was held recently in Moscow (Lesik, 1972). It was called on the initiative of the Main Administration of the Hydrometeorological Service of the U.S.S.R. Council of Ministers. Scientific specialists from the U.S.S.R. Hydrometeorological Center, the Main Astronomical Observatory of the U.S.S.R. Academy of Sciences, the Institute of Terrestrial Magnetism, the Ionosphere and Radio Wave Propagation Institute of the U.S.S.R. Academy of Sciences, the Main Geophysical Observatory, the Arctic and Antarctic Scientific Research Institute, the Central Aerological Observatory, the Institute of Biology of Internal Waters of the U.S.S.R. Academy of Sciences, the Marine Hydrophysical Institute Academy of Sciences of the Ukranian S.S.R., the Institute of Applied Geophysics, Leningrad and Kazan' State Universities, the Advanced Marine Engineering Institute, the Scientific Research Heliometeorological Station at Gornaya Shoriya, and the Kherson Agrometeorological Station presented different reports at its sessions.

Fifty reports and communications were presented at the conference, which lasted 3 days. Representatives of different scientific research institutes and laboratories, participated in their discussion.

In a lengthy resolution, the conference noted that investigations of different aspects of the "SunEarth's 'Atmosphere" problem performed over a period of several decades in the U.S.S.R. and abroad make it possible to assert with assurance that solar activity and other space-geophysical factors exert a substantial influence on atmospheric processes. Allowance for these factors is 
of great importance in preparing weather forecasts.

It was noted at the conference that the Soviet scientists M. S. Eygenson, V. Uy. Vize, L. A. Vitel's, B. M. Rubashov, A. I. Ol', I. V. Maksimov, A. A. Girs, T. V. Pokrovskaya, M. N. Gnevyshev, A. V, D'yakov, P. P. Predtechenskiy, E. R. Mustel', and R. F. Usmanov have made a substantial contribution to the study of these problems. Many interesting and promising investigations have been made by the younger generation of scientists.

While noting the considerable attainments of Soviet science in solving the problem of solar/ terrestrial relationships, and in taking into account their role in the practical activity of the U.S.S.R. Hydrometeorological Service, the conference nevertheless pointed out: serious shortcomings.

For example, in the U.S.S.R. Hydrometeorological Service and in the U.S.S.R. Academy of Sciences there is still no organization for coordinating and planning work of solar specialists or for putting into practice the results already achieved by them. We have not properly organized the collection, processing, and routine use of solar and geophysical information in weather forecasting work. As a result, in the development and improvement of forecasting methods, allowance is unfortunately not made for the role of solar/atmospheric relationships; they are usually ignored when preparing weather forecasts by synoptic and numerical methods.

Accordingly, the conference deemed it desirable to broaden work on the study of the influence of a complex of space-geophysical factors on the atmosphere and weather; one of the most important problems facing the U.S.S.R. Hydrometeorological Service. The conference has laid out a broad program of investigations for these purposes using the latest instruments, rockets, space vehicles, electronic computers, and so on.

In the conference's resolution it was noted that there must be the fastest possible training of highly skilled specialists on the problem "Sun/ lower atmosphere" through the graduate school level; there is also an urgent need for organizing annual courses on heliometeorology for workers in scientific, academic, and operational units of the U.S.S.R. Hydrometeorological Service.

Beginning with 1973, plans call for publication of specialized collections of articles on heliometeorology and broadening of publication of materials on solar/terrestrial relationships in the journals Meteorologiya $i$ Gidrologiya and Fiziak Atmosfery $i$ Okeana. The U.S.S.R. Hydrometeorological Service, the Main Geophysical Observatory, and the Arctic and Antarctic Scientific Research Institute have been delegated the task of generalizing investigations on this problem and preparing a systematic manual for operational workers in the U.S.S.R. weather forecasting service.

The conference deemed it desirable to create in the key institutes of the. Hydrometeorological Service a network of heliometeorological stations (observatories) and departments of solar/terrestrial relationships at some universities and hydrometeorological institutes. Solar -specialists expect great assistance from the institutes of the U.S.S.R. Academy of Sciences and the academies of science of some union republics, particularly in the plan for forecasting solar activity.

Considering the results of the first All-Union conference, it has been decided to issue a collection of articles by its participants and in the future to hold such conferences regularly, every 2 or $3 \mathrm{yr}$, and in the time intervals between them to hold working conferences on individual aspects of the problem.

In its resolution, the conference especially noted the positive role played by discussion of the problem of solar/terrestrial relationships and their prediction on the pages of the newspapers Sel'skaya Zhizn', Pravda, and Literaturnaya Gazeta (JuneOct. 1972). The questions raised in the press and the critical comments made by the newspapers have favored a broader discussion of this problem and its role in weather forecasting.

The conference was concluded by words from Academician Ye. K. Fedorov, chief of the Main Administration of the Hydrometeorological Service of the U.S.S.R. Council of Ministers. 
APPENDIX B-OBSERVED AND WELL-DEFINED SECTOR

BOUNDARIES a

\begin{tabular}{|c|c|c|c|c|}
\hline Year & $\begin{array}{c}\text { Day of } \\
\text { year }\end{array}$ & Sign $^{\mathrm{B}}$ & Däte & Time $^{c}$ \\
\hline \multirow[t]{4}{*}{1962} & 253 &,+- & Sept. 10 & $8-1$ \\
\hline & 269 &,-+ & Sept. 26 & $3-4$ \\
\hline & 281 &,+- & Oct. 8 & $4-5$ \\
\hline & 293 &,-+ & Oct. 20 & $8-1$ \\
\hline \multirow[t]{3}{*}{1963} & 336 &,-+ & Dec. 2 & $8-1$ \\
\hline & 346 &,+- & Dec. 12 & 4-3 (gap) \\
\hline & 354 &,-+ & Dec. 20 & $1-2$ \\
\hline \multirow[t]{16}{*}{1964} & 007 &,+- & Jan. 7 & $7-8$ \\
\hline & 016 &,-+ & Jan. 16 & $2-2$ (gap) \\
\hline & 023 &,+- & Jan. 23 & $3-4$ \\
\hline & 035 &,+- & Feb. 4 & $2-3$ \\
\hline & 284 &,-+ & Oct. 10 & 6-7 (1-day gap) \\
\hline & 291 &,+- & Oct. 17 & $7-8$ \\
\hline & 297 &,-+ & Oct. 23 & 6-8 (1-day gap) \\
\hline & 306 &,+- & Nov. 1 & $5-6$ \\
\hline & 312 &,-+ & Nov. 7 & 2-1 (gap) \\
\hline & 320 &,+- & Nov. 15 & $5-6$ \\
\hline & 325 &,-+ & Nov. 20 & 3-2 (gap) \\
\hline & 332 &,+- & Nov. 27 & $7-8$ \\
\hline & 341 &,-+ & Dec. 6 & $4-5$ \\
\hline & 345 &,+- & Dec. 10 & $8-1$ \\
\hline & 349 &,-+ & Dec. 14 & $8-1$ \\
\hline & 361 &,+- & Dec. 26 & $1-2$ \\
\hline \multirow[t]{10}{*}{1965} & 002 &,-+ & Jan. 2 & $1-2$ \\
\hline & 008 & $+;-$ & Jan. 8 & $1-2$ \\
\hline & 012 &,-+ & Jan. 12 & $2-3$ \\
\hline & 032 &,+- & Feb. 1 & $8-1$ \\
\hline & 125 &,+- & May 5 & $4-5$ \\
\hline & 153 &,+- & June 2 & $8-1$ \\
\hline & 161 &,-+ & June 10 & $2-3$ \\
\hline & 230 &,-+ & Aug. 18 & 7-6 (gap) \\
\hline & 235 &,+- & Aug. 23 & 5-7 (gap) \\
\hline & 259 &,-+ & Sept. 16 & $2-3$ \\
\hline \multirow[t]{16}{*}{1966} & 001 &,+- & Jan. 1 & 6-7 (1-day gap) \\
\hline & 032 &,+- & Feb. 1 & $4-5$ \\
\hline & 043 &,-+ & Feb. 12 & $2-3$ \\
\hline & 062 &,+- & Mar. 3 & $3-4$ \\
\hline & 067 &,-+ & Mar. 8 & $2-3$ \\
\hline & 089 &,+- & Mar. 30 & $2-3$ \\
\hline & 099 &,-+ & Apr. 9 & $1-2$ \\
\hline & 127 &,-+ & May 7 & $8-1$ \\
\hline & 249 &,-+ & Sept. 6 & $5-6$ \\
\hline & 257 &,+- & Sept. 14 & $6-7$ \\
\hline & 276 &,-+ & Oct. 3 & $6-7$ \\
\hline & 285 &,+- & Oct. 12 & $2-3$ \\
\hline & 303 &,-+ & Oct. 30 & $5-6$ \\
\hline & 312 &,+- & Nov. 8 & $4-5$ \\
\hline & 331 &,-+ & Nov. 27 & $7-8$ \\
\hline & 338 &.+- & Dec. 4 & $3-4$ \\
\hline
\end{tabular}

\begin{tabular}{|c|c|c|c|c|}
\hline Year & $\begin{array}{c}\text { Day of } \\
\text { year }\end{array}$ & Sign $^{b}$ & Date & Time $^{e}$ \\
\hline \multirow[t]{12}{*}{1967} & 001 &,+- & Jan. 1 & $7-8$ \\
\hline & 013 & & Jan. 13 & $3-4$ \\
\hline & 018 &,-+ & Jan. 18 & 2-3 (1-day gap) \\
\hline & 081 &,-+ & Mar. 22 & $7-8$ \\
\hline & 216 &,-+ & Aug. 4 & $5-6$ \\
\hline & 242 &,-+ & Aug. 30 & 2-3 (1-day gap) \\
\hline & 249 &,+- & Sept. 6 & $6-7$ \\
\hline & 270 &,-+ & Sept. 27 & $3-4$ \\
\hline & 276 &,+- & Oct. 3 & $1-2$ \\
\hline & 297 &,-+ & Oct. 24 & $2-3$ \\
\hline & 324 &,-+ & Nov. 20 & $4-5$ \\
\hline & 338 &,+- & Dec. 4 & $5-6$ \\
\hline iso & & & & \\
\hline \multirow[t]{23}{*}{1968} & 001 &,+- & Jan. 1 & 6-5 (gap) \\
\hline & 028 &,+- & Jan. 28 & $8-1$ \\
\hline & 042 &,-+ & Feb. 11 & $3-4$ \\
\hline & 057 &,+- & Feb. 26 & $6-7$ \\
\hline & 070 &,-+ & Mar. 10 & $4-5$ \\
\hline & 083 &,+- & Mar. 23 & $5-6$ \\
\hline & 096 &,-+ & Apr. 5 & $7-8$ \\
\hline & 112 &,+- & Apr. 21 & $3-4$ \\
\hline & 123 &,-+ & May 2 & $1-2$ \\
\hline & 138 &,+- & May 17 & $5-6$ \\
\hline & 185 &,-+ & July 3 & $3-4$ \\
\hline & 191 &,+- & July 9 & $8-1$ \\
\hline & 199 &,-+ & July 17 & 4-5 \\
\hline & 207 &,+- & July 25 & $4-5$ \\
\hline & 213 &,-+ & July 31 & $7-8$ \\
\hline & 226 &,-+ & Aug. 13 & $7-8$ \\
\hline & 234 &,+- & Aug. 21 & $2-3$ \\
\hline & 263 &,+- & Sept. 19 & $2-3$ \\
\hline & 290 &,+- & Oct. 16 & $5-6$ \\
\hline & 318 &,+- & Nov. 13 & $2-3$ \\
\hline & 334 &,-+ & Nov. 29 & 6-8 (gap) \\
\hline & 345 &,+- & Dec. 10 & $2-3$ \\
\hline & 359 &,-+ & Dec. 24 & $6-7$ \\
\hline \multirow[t]{16}{*}{1969} & 006 &,+- & Jan. 6 & $5-6$ \\
\hline & 023 &,-+ & Jan. 23 & $8-1$ \\
\hline & 033 &,+- & Feb. 2 & $5-6$ \\
\hline & 050 &,-+ & Feb. 19 & $2-3$ \\
\hline & 090 &,+- & Mar. 31 & $6-7$ \\
\hline & 110 &,-+ & Apr. 20 & 7-1 (gap) \\
\hline & 119 &,+- & Apr. 29 & $3-4$ \\
\hline & 127 &,-+ & May 7 & 6-3 (gap) \\
\hline & 132 &,+- & May 12 & 8-2 (gap) \\
\hline & 138 &,-+ & May 18 & $6-7$ \\
\hline & 147 &,+- & May 27 & $1-2$ \\
\hline & 165 &,-+ & June 14 & $3-4$ \\
\hline & 192 &,-+ & July 11 & $2-3$ \\
\hline & 202 &,+- & July 21 & $5-6$ \\
\hline & 219 &,-+ & Aug. 7 & $6-7$ \\
\hline & 248 &,-+ & Sept. 5 & $3-4$ \\
\hline
\end{tabular}




\begin{tabular}{c|c|c|l|l}
\hline Year & $\begin{array}{c}\text { Day of } \\
\text { year }\end{array}$ & Sign $^{\mathrm{b}}$ & \multicolumn{1}{|c|}{ Date } & \multicolumn{2}{|c}{ Time $^{\mathrm{e}}$} \\
\hline & 303 &,-+ & Oct. 30 & $8-1$ \\
& 330 &,-+ & Nov. 26 & $5-6$ \\
& 343 &,+- & Dec. 9 & $1-2$ \\
& 356 &,-++ & Dec. 22 & $7-8$ \\
& & & & \\
& 040 &,-+ & Feb. 9 & $7-8$ \\
& 067 &,-+ & Mar. 8 & $8-1$ \\
120 &,-+ & Apr. 30 & $3-4$ \\
& 131 &,+- & May 11 & $6-7$ \\
& 158 &,+- & June 7 & $6-7$ \\
& 243 &,+- & Aug. 31 & $8-5$ (gap) \\
& 309 &,-+ & Nov. 5 & $3-4$ \\
& 328 &,+- & Nov. 24 & $3-4$ \\
\hline
\end{tabular}

"All sector boundaries listed have at least 4 days of opposite field polarity on each side of the boundary.

${ }^{b}$ Plus indicates away from the Sun; minus indicates toward the Sun.

${ }^{c}$ Time is indicated in 3-hr intervals. The notation 8-1 means that the boundary occurred between the last 3-hr interval of that day and the first 3-hr interval of the next day.

\section{REFERENCES}

Berko, F. W., and R. A. Hoffman, 1974, "Dependence of Field-Aligned Electron Precipitation Occurrence on Season and Altitude," J. Geophys. Res., 79, pp. 37493754.

Bigelow, F. H., 1898, "Solar and Terrestrial Magnetism in Their Relations to Meteorology," U.S. Department of Agriculture, Weather Bureau, Bulletin No. 21.

Bossolasco, M., I. Dagnino, A. Elena, and G. Flocchini, 1972, "Solar Flare Control of Thunderstorm Activity," Instituto Universitario Navale Di Napoli, 1st. Di Meteorologia E Oceanografia, pp. 213-218.

Hines, C. O., 1973, "Comments on 'A Test of an Apparent Response of the Lower Atmosphere to Solar Corpuscular Radiation'," J. Atmos. Sci., 30, pp. 739-744.

Kelvin, The Lord, 1892, "The Anniversary of the Royal Society," Nature, 47, pp. 106-111.

Mansurov, S. M., L. G. Mansurova, and G. S. Mansurov, 1972, "Connection Between the Interplanetary Magnetic Field Sector Structure and Atmospheric Pressure at Conjugate Points and Its Statistical Analysis," Preprint 8, Institute of Terrestrial Magnetism, Ionosphere and Radiowave Propagation, Akademgorodok, U.S.S.R.

Markson, R., 1971, "Considerations Regarding Solar and Lunar Modulation of Geophysical Parameters, Atmospheric Electricity and Thunderstorms," Pure Appl. Geophys., 84, pp. 161-202.

Monin, Andrei S., 1972, Weather Forecasting as a Problem in Physics, MTT Press.

Mustel, E. R., 1972, "On the Reality of the Influence of Solar Corpuscular Streams Upon the Lower Layers of the Earth's Atmosphere," Pub. No. 24, Astronomical Council, U.S.S.R. Acad. of Sci., Moscow.

Reiter, R., 1973, "Increased Influx of Stratospheric Air Into the Lower Troposphere After Solar $\mathrm{H}_{\alpha}$ and X-Ray Flares," unpublished paper.

Roberts, W. O., and R. H. Olson, 1973a, "Geomagnetic Storms and Winter-Time 300-mb Trough Development in the North Pacific-North America Area," J. Atmos. Sci., 30, pp. 135-140.

Roberts, W. O., and R. H. Olson, 1973b, New Evidence for Effects of Variable Solar Corpuscular Emission Upon the Weather," Rev. Geophys. Space Phys., 11, pp. $731-740$.

Rothwell, P., and C. Greene, 1966, "Spatial and Temporal Distribution of Energetic Electrons in the Outer Radiation Belt," Univ. of Southhampton Report.

Rubashev, B. M., 1964, "Problems of Solar Activity," NASA TT F-244.

Schuurmans, C. J. E., 1969, "The Influence of Solar Flares on the Tropospheric Circulation," Royal Netherland Meteorological Institute, DeBilt, the Netherlands.

Severny, A., J. M. Wilcox, P. H. Scherrer, and D. S. Colburn, 1970, "Comparison of the Mean Photospheric Magnetic Field and the Interplanetary Magnetic Field," Solar Pliys., 15, pp. 3-14.

Shapiro, R., 1972, "A Test of an Apparent Response of the Lower Atmosphere to Solar Corpuscular Radiation," J. Atmos. Sci., 29, pp. 1213-1216.

Shapiro, R., and H. Stolov, 1972, to be published.

Svalgaard, L., 1972, "Interplanetary Magnetic-Sector Structure, 1926-1971,"J. Geophys. Res., 77, pp. 40274034.

Svalgaard, L., 1973, "Solar Activity and the Weather" (Proc. 7th ESLAB Symp., May 22-25, 1973, Saulgau, West Germany), D. Reidel, Dordrecht, Holland, to be published.

Wilcox, J. M., 1968, "The Interplanetary Magnetic Field. Solar Origin and Terrestrial Effects," Space Sci. Rev., 8, pp. 258-328.

Wilcox, J. M., 1971, "Solar Sector Magnetism," Comments on Astrophysics and Space Physics, 3, pp. 133139.

Wilcox, J. M., and D. S. Colburn, 1972, "Interplanetary Sector Structure at Solar Maximum," J. Geophys. Res., 77, pp. 751-756.

Wilcox, J. M., and R. Howard, 1968, "A Large-Scale Pattern in the Solar Magnetic Field," Solar Phys., 5, pp. 564-574.

Wilcox, J. M., and N. Ness, 1965, "Quasi-Stationary Corotating Structure in the Interplanetary Medium, J. Geophys. Res., 70, pp. 5793-5805.

Wilcox, J. M., P. H. Scherrer, L. Svalgaard, W. O. Roberts, and R. H. Olson, 1973a, "Solar Magnetic Sector Structure: Relation to Circulation of the Earth's Atmosphere," Science, 180, pp. 185-186.

Wilcox, J. M., P. H. Scherrer, L. Svalgaard, W. O. Roberts, R. H. Olson, and R. L. Jenne, 1973b, "Influence of Solar Magnetic Sector Structure on Terrestrial Atmospheric Vorticity," I. Atmos. Sci., to be published. 